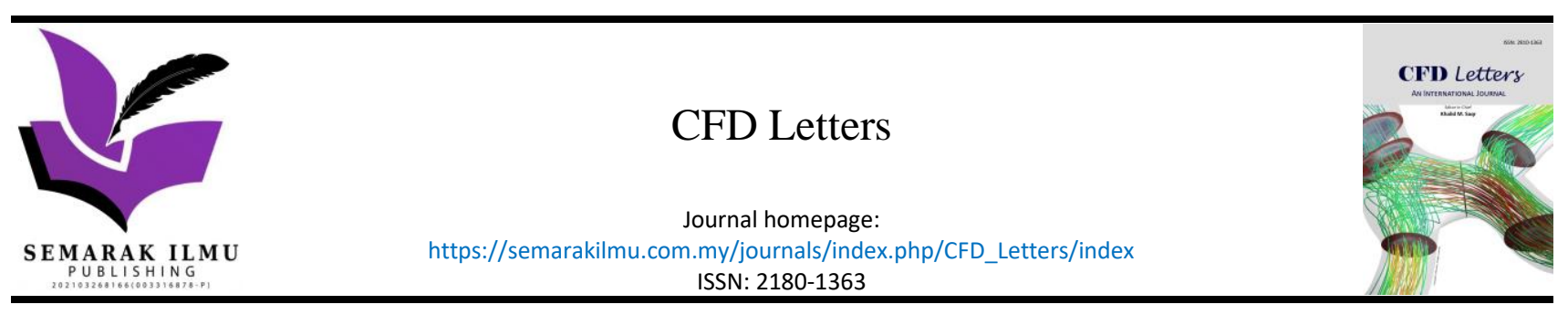

\title{
Characterization of a Commercial Axial Flow PAT Through a Structured Methodology Step-by-Step
}

\author{
Diego Penagos-Vásquez ${ }^{1,}{ }^{*}$, Jonathan Graciano-Uribe ${ }^{1}$, Edward Torres ${ }^{2}$ \\ Faculty of Engineering, Department of Mechatronics and Electromechanics, Research group - MATyER, Instituto Tecnológico Metropolitano, \\ 050034 Medellín, Colombia \\ 2 Department of Mechanical Engineering, Research Group - GEA, Universidad de Antioquia, 050010 Medellín, Colombia
}

\section{\begin{tabular}{l} 
ARTICLE INFO ABSTRACT \\
\hline
\end{tabular}}

\section{Article history:}

Received 15 September 2021

Received in revised form 22 November 2021

Accepted 24 November 2021

Available online 7 January 2022

\section{Keywords:}

PAT; Best efficiency point; Control volume; Axial flow; Site conditions; Structured methodology

\begin{abstract}
A centrifugal pump as a turbine (PAT) is the inverse operation of a conventional pump, which takes advantage of the hydraulic energy of water to convert it into rotational mechanical energy and subsequently into electrical energy, through a generator. The CFD analysis allows predicting the fluid dynamic behavior and calculating the operating characteristic curve of the PAT, thus reducing costs in experimental setups. In the literature, the operation of the turbomachine in pump and turbine mode is evidenced. However, there is no methodology applied in commercial axial flow pumps that exposes a structured step-by-step to carry out the numerical and fluid dynamic analysis. In this study, a novel structured methodology is developed describing the numerical and CFD analysis of a commercial axial flow centrifugal pump, which allows validating the characteristic curve in pump mode and then obtaining the site conditions in turbine mode, for its application in small hydroelectric power plants. As a result, in pump mode, an error of less than $8 \%$ is obtained between the manufacturer's curve and the numerical curve. In turbine mode, the best performance is around $73 \%$. The aim is to propose a replicable algorithm in future works that allows the proper analysis in commercial axial flow pumps.
\end{abstract}

\section{Introduction}

The need to transform a primary energy resource to obtain electricity is recurrent nowadays [1]. Primary sources come from renewable sources, where energy from the air, sun, and water is used, and non-renewable sources, mostly from petroleum and coal combustion that leaves as a residue the emission of polluting gases. The above has led scientists to study, develop and improve electrical generation equipment that employs clean energy [2].

Hydraulic sources are a highly trending field of study, given that electric demand grows every year. It has excellent stability in the market, adding fields such as pumped storage [3,4]. Also, hydraulic energy is energy efficient, provides a wide range of operations, and has no emission of

\footnotetext{
* Corresponding author.

E-mail address: diegopenagos8757@correo.itm.edu.co (Diego Penagos-Vásquez)
}

https://doi.org/10.37934/cfdl.14.1.119 
noxious gases [5]. The above is focused on contributing to the seventh sustainable development goal: affordable and clean energy [6].

The global and local hydropower context is displayed employing graphs. Figure 1(a) reports the 20 countries with the largest installed hydropower generation capacity and pumped storage in 2019. A growth of $1.2 \%$ over the previous year was obtained. China was contributing $27.2 \%$. In this analysis, Colombia, the country of reference, ranks $20^{\text {th }}$ with $11.92 \mathrm{GW}$, equivalent to $0.9 \%$ of the total, is the third place in South America [7, 8]. Figure 1(b) represents the map concerning its installed capacity and sources of electricity generation in 2020. The energy coming from hydraulic sources is equivalent to $69 \%$ of the total [9]. Besides, it is observed that the south is not suitable for generating energy from this source, even though it has suitable geography. This behavior is due to the high investment cost and the relatively small population of these regions [10].

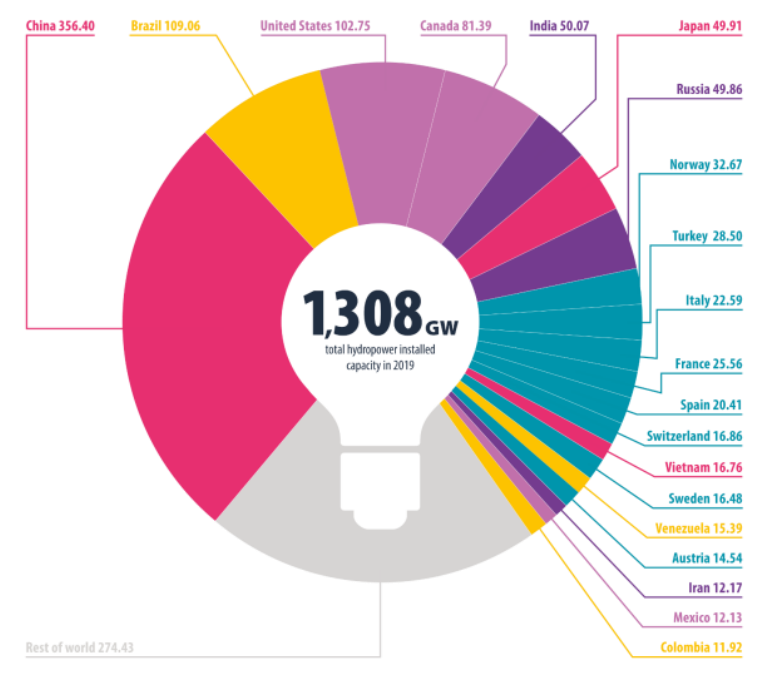

(a)

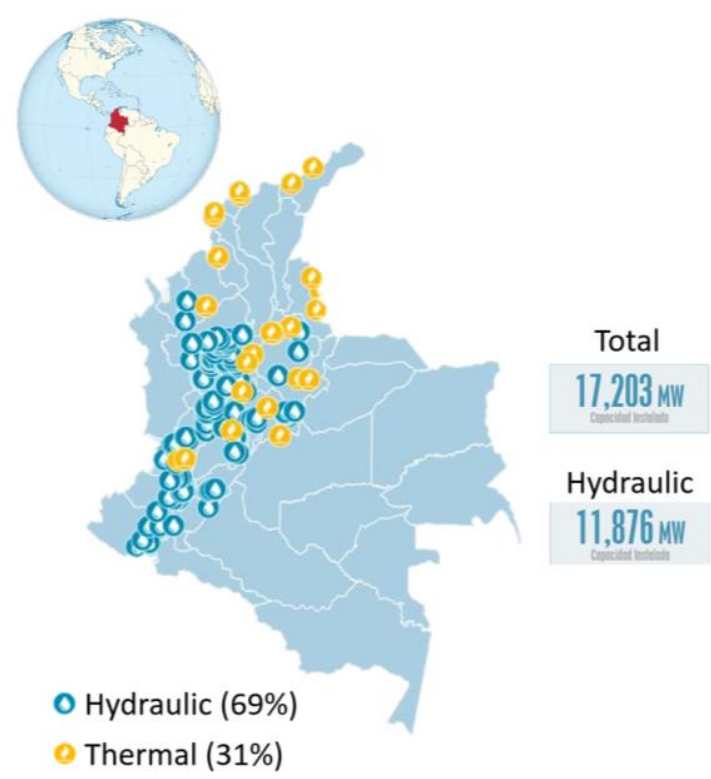

(b)

Fig. 1. Installed hydroelectric capacity: (a) worldwide [7, 8] and (b) Colombia [9]

How can a turbomachine be selected to supply electricity to the regions that are part of the noninterconnected zones, using a device with high availability, low acquisition cost, easy maintenance, and marketable?

In literature, the selection of different turbomachines has been found through graphs, depending on the site conditions: flow and head. Additionally, an approximate hydraulic power can be obtained. Figure 2 shows the selection graph for hydraulic turbomachines. The horizontal axis quantifies the flow rate, while the vertical measures the turbine head. Diagonal lines indicate the power that the turbine could convert into effective electrical work, without considering losses in general. Figure 2(a) details the traditional turbines, such as Pelton and Francis, widely used in large-scale hydroelectric generation. However, their installation requires a large initial investment and civil intervention [11]. In Figure 2(b), the pump as turbine (PAT) selection graph is revealed [12]. These turbomachines can generate hydraulic power like conventional turbines, requiring even lower flow rates. On the other hand, PAT has the disadvantage of not being efficient with part-load conditions, so site conditions must be kept constant [13].

In this context, pumps can be radial, mixed, or axial flow. Axial flow pumps are designed to provide a higher flow rate at a low head [14], mainly applicable in low mountainous areas, irrigation, 
flood control, and water detour [15]. However, manufacturers do not provide the characteristic curve when purchasing a centrifugal pump if it is operated in turbine mode for hydroelectric power generation [16]. Therefore, it is necessary to perform an experimental setup to determine the site conditions in turbine mode, where this is usually complex and costly, due to the acquisition of the pump and laboratory instruments. A numerical study and Computational fluid dynamics (CFD), allow the reconstruction of the characteristic curve in pump and turbine mode and to predict the behavior of the fluid inside the turbomachine, respectively.

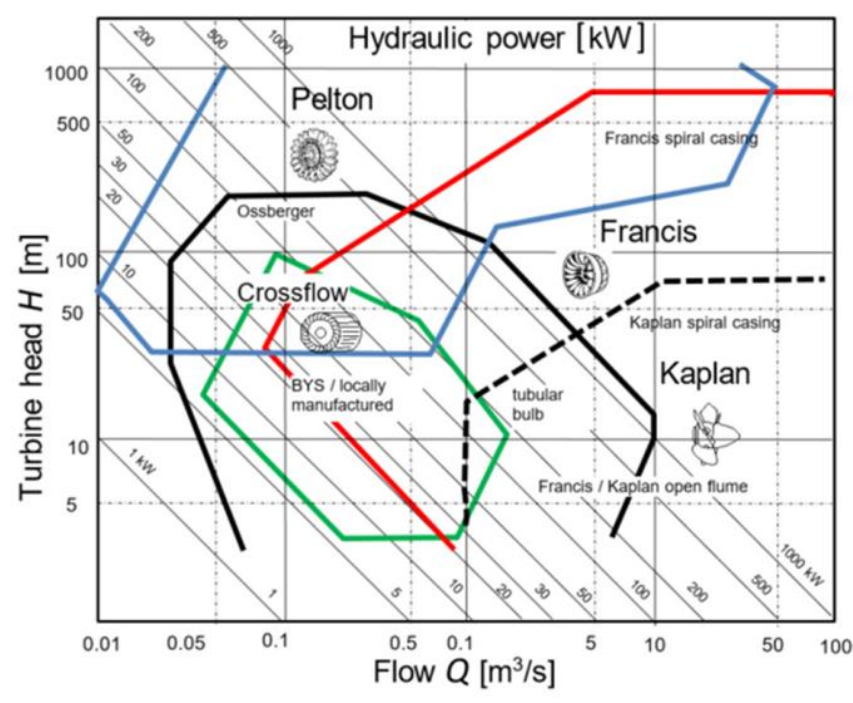

(a)

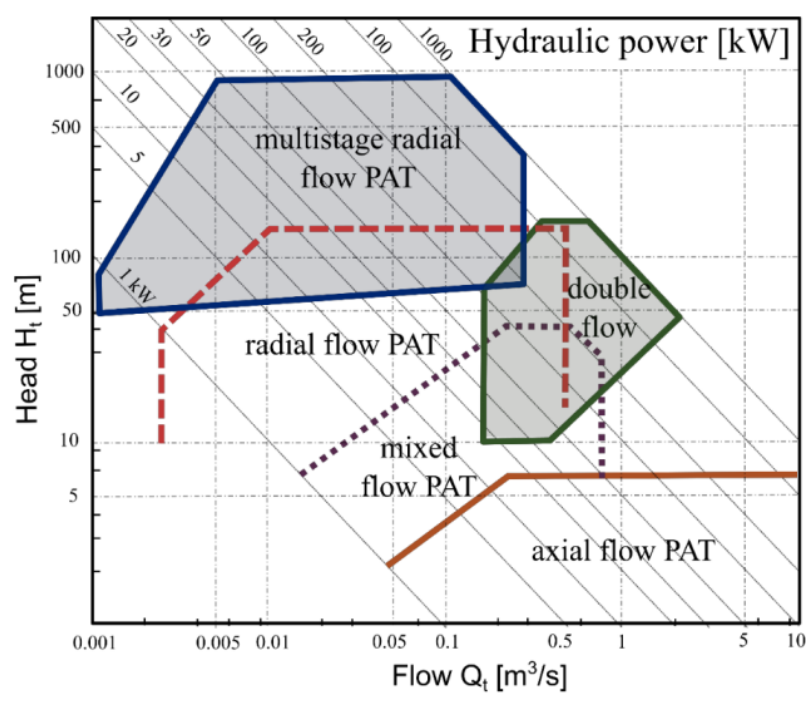

(b)

Fig. 2. Turbomachine selection for (a) traditional turbines [11] and (b) PATs [12]

In the literature, numerical and CFD studies have been applied to radial [17-22], mixed [23, 24], and axial [25-32] centrifugal pump as turbine, as well as in a review article [33], where the behavior of pressure, velocity, and the experimental characteristic curve have been validated. On the other hand, the study of the radial Flow PAT from the manufacturer's curve has been shown to predict the site conditions in turbine mode for specific velocities of 9-65 ( $\left.\mathrm{rpm} \mathrm{m} \mathrm{m}^{3 / 4} \mathrm{~s}^{-1 / 2}\right)$ [34, 35]; Similarly, another study was based on numerical correlations employing a flowchart. However, both studies are not replicable in mixed and axial flow pumps because the rotational speed of the impeller would be excessively high according to the equations proposed, reaching more than $20000 \mathrm{rpm}$ [36]. In addition, a step-by-step diagram has been developed to optimize the geometry of a radial $[37,38]$ and axial impeller [39] involving CFD analysis and neural networks. Finally, methodologies for the selection of pump conditions have been plotted, starting from site conditions in turbine mode for water distribution networks [40].

Other studies have shown specific behaviors of radial Flow PATs: besides validating the experimental curve, the mathematical approach of the particle has been evidenced, employing the Euler's pump and turbine equation model, which relates the triangle of velocities in the impeller, obtaining error lower than $6 \%$ in head when using the $k-\varepsilon$ turbulence model [41]; the behavior of the turbomachine with unsteady flow has been analyzed, emphasizing on the impeller and volute sections, using the $k-\omega$ turbulence model. The authors validate the experimental and CFD characteristic curve, obtaining an error of less than 5\% [42]; the erosion behavior inside the machine has been investigated, showing the velocity and trajectory of the particle, and the regions of the volute and impeller where the greatest structural damage is generated [43]. 
However, no structured methodology to follow for the proper selection of an axial flow PAT from the pump manufacturer's catalog was found since the studies are more related to radial flow centrifugal pumps. The papers cited employed methodologies applicable to each case, but there is no evidence of a methodology defined step-by-step for numerical and fluid dynamic simulation replicable to any commercial axial flow centrifugal pump.

This work seeks to characterize a commercial axial flow centrifugal pump operating as a turbine, through a structured step-by-step methodology, which allows the adequate selection of the PAT from the manufacturer's characteristic curve. As a novelty, the computational modeling of the control volumes with the use of the commercial catalog database is proposed to predict the site conditions in turbine mode, through numerical and CFD simulation, saving time in experimental tests and evaluating the relevance of an axial PAT before its purchase and installation. With this, a replicable methodology is proposed for the supply of electric power in places that are not part of the national interconnected system since these turbomachines meet the requirements for remote areas.

\section{Methodology}

ANSYS $^{\circledR}$ software was used for the computational analysis. The proposed methodology can be visualized in Figure 3, where a flow chart is shown that represents the step-by-step of each of the procedures to be followed. A total of seven (7) steps can be observed, represented by blocks, and connected by arrows, where the illustration, the procedure, and the corresponding step are detailed in each one. The characteristic curve given by the manufacturer is taken as the origin and ends with obtaining the curve in turbine mode. Additionally, a return from step 5 to step 2 can be seen, where this occurs if the condition of comparative error in the best efficiency point (BEP) between the numerical and experimental (manufacturer) of less than $10 \%$ is not met. Finally, there is a theoretical block (step 1, applying the new procedure), two modeling blocks (step 2 and 3), two simulation setup blocks (steps 4 and 6), and two result blocks (steps 5 and 7).

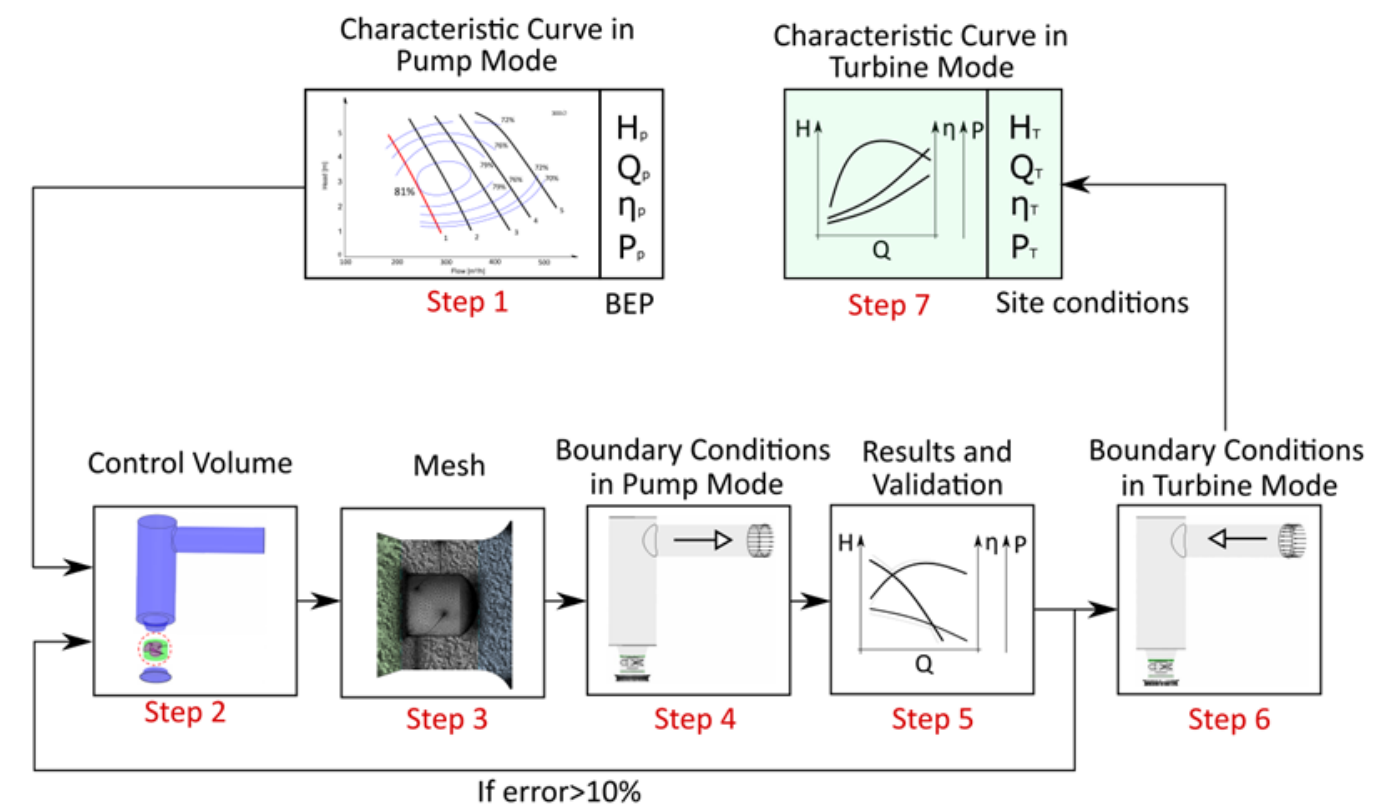

Fig. 3. Methodological diagram proposed for commercial axial flow PAT analysis

Step 1. Consists of obtaining the characteristic curve provided by the manufacturer of the axial flow pump through the turbomachine catalog. Then, the BEP of the curve is extracted, where the 
variables of flow, head, efficiency, and power are related. This information provides a reference point to validate the pump mode behavior detailed in step 5 .

Step 2. The control volume of the impeller and housing fluid is parameterized based on each component's dimensions from the catalog. In many cases, it is impossible to access the impeller information, so an approximate geometry can be produced since the flow particles are not being analyzed.

Step 3. The control volume is discretized, considering the areas near the impeller, and the mesh metrics.

Step 4. The boundary conditions and numerical setup for pump mode operation are established and the simulation is performed.

Step 5. Numerical results are obtained and compared concerning the manufacturer's characteristic curve and the BEP information in step 1. If the relative error obtained in the head is less than the proposed $10 \%$, the operation in turbine mode can be continued; otherwise, it is necessary to review the geometry in step 2 and follow the steps again. Also, it is essential to check the pressure and velocity contours to verify the fluid dynamic behavior (result block).

Step 6. The boundary conditions are established in turbine mode, where suction and discharge are exchanged, concerning the pump mode. Then, the numerical simulation is performed for different flow rate values.

Step 7. Numerical and fluid dynamic results are obtained, reconstructing the head, efficiency, and power curves. Finally, the site conditions in turbine mode are obtained and validated to the graph of PAT selection, shown in Figure 2 (result block).

\subsection{Step 1 and 2: Characteristics Curves of Pump and Control Volume}

The commercial axial flow pump selected for this case study is the reference AVS 300-350-III, manufactured by DP PUMPS [44]. Figure 4(a) presents the physical image of the turbomachine, where the impeller is constructed with three vanes. Figure 4(b) details the characteristic curve, where additional points selected for the numerical simulation can be observed. Finally, BEP data is as follows: pump head $\left(H_{p}\right) 2.84 \mathrm{~m}$, flow rate $\left(Q_{p}\right) 246.5 \mathrm{I} \mathrm{s}^{-1}$, efficiency $\left(\eta_{p}\right) 81 \%$, hydraulic power $\left(P_{p}\right)$ $8.37 \mathrm{~kW}$, used to compare the results of step 5. The curve presented, according to the manufacturer, only includes information on the pump without the motor attached, so the efficiency reported is the hydraulic one and does not include electrical data.

Studies, where 3D scans are used for modeling the turbomachine control volume, have been reported [43]. However, for this work the manufacturer's database was used, to obtain an approximate geometry, based on dimensions that allow modeling the pump as close as possible to reality. With this, the aim is to characterize the turbomachine before its acquisition in order to reduce costs in experimental tests and to predict the site conditions in turbine mode. On the other hand, it was not possible to access the information of the impeller, so an approximate geometry was made because the present study does not consider the analysis of particles.

Although the geometry is plane-based, it is predictable to have an error between numerical and experimental data, so a part of it corresponds to three-dimensional modeling. Figure 5 shows the pump schematic provided by the manufacturer, where the red arrows refer to the dimensions represented in Table 1. It is possible to observe that not all the measurements are reported, so it was necessary to use the Inkscape software to complete the dimensions. Figure 6 details the overall computational fluid model parameterized in the SpaceClaim module of ANSYS ${ }^{\circledR}$. Housing is separated into two sections because the geometry close to the impeller is relatively significant. 


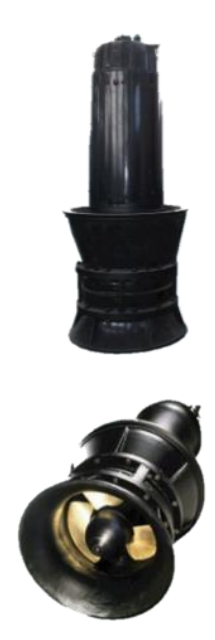

(a)

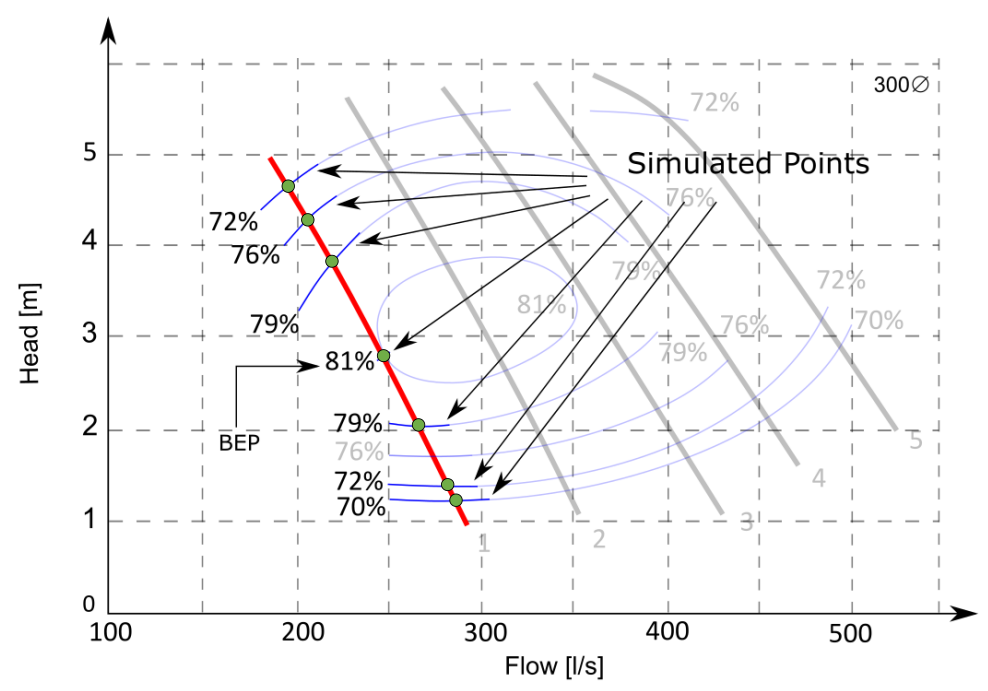

(b)

Fig. 4. Axial flow pump: (a) physical image and (b) characteristic curve [44]

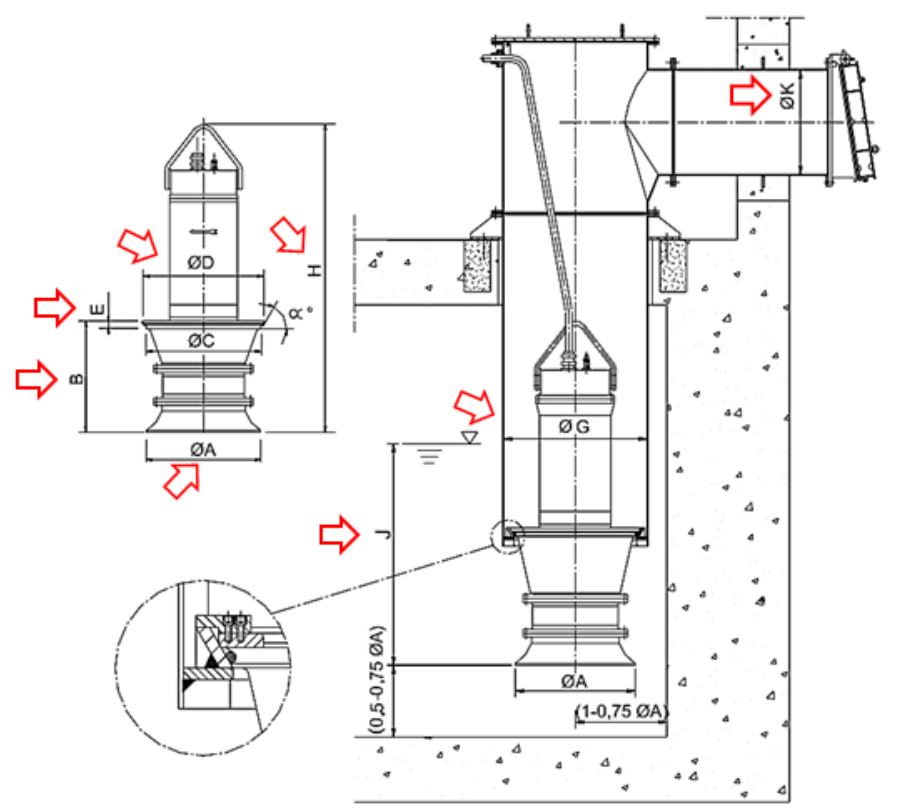

Fig. 5. sketch extracted from the manufacturer's catalog

Table 1

Pump dimensions

\begin{tabular}{lllllllll}
\hline Measure & $\phi \mathrm{A}$ & $\mathrm{B}$ & $\phi \mathrm{D}$ & $\mathrm{E}$ & $\phi \mathrm{G}$ & $\mathrm{H}$ & $\mathrm{J}$ & $\phi \mathrm{K}$ \\
\hline Value $[\mathrm{mm}]$ & 420 & 457 & 520 & 43 & 600 & 1635 & 800 & 400 \\
\hline
\end{tabular}




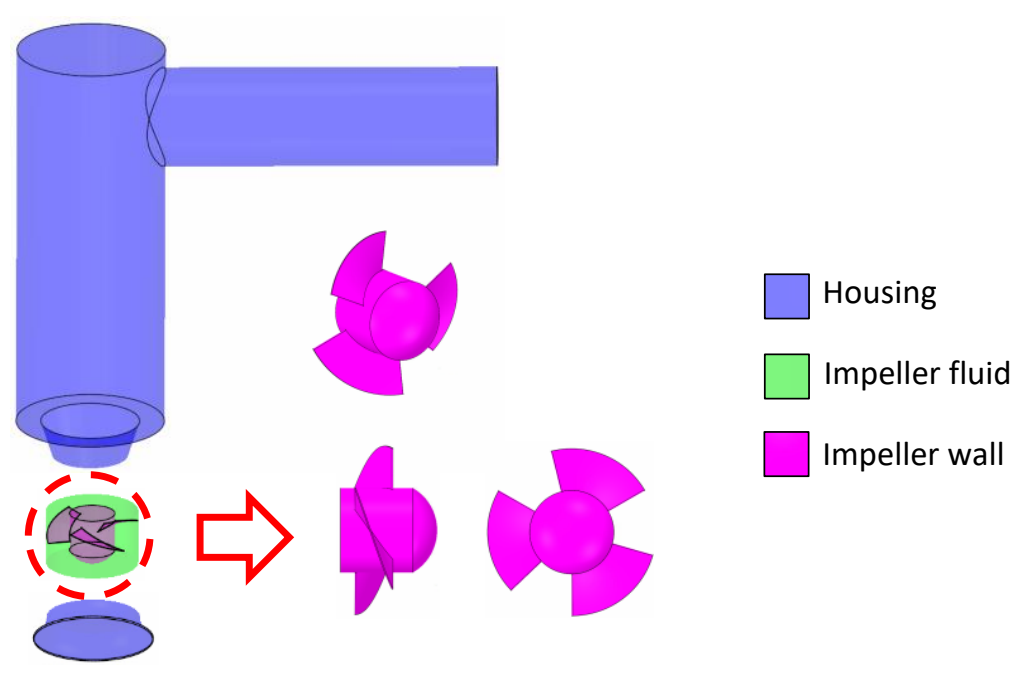

Fig. 6. Computational model: (a) pump schematic and (b) control volume

\subsection{Step 3: Mesh}

The pump control volume mesh is developed in the Meshing module of ANSYS ${ }^{\circledR}$. The mesh study is carried out to obtain a good balance between the closeness of the result to the BEP efficiency and an optimal number of elements, and simulation time. Table 2 presents the evaluation of five (5) meshes, where mesh 4 was selected in the present study, due to the closeness of the efficiency and relative error concerning mesh 5, while mesh 3 showed a greater difference. Although a lower error is observed in mesh 1, it was not considered, because the size of the elements did not show a correct fluid dynamic behavior and the mesh metric was relatively lower than the software parameters. Finally, mesh 5 was not selected due to the high simulation time. The optimal mesh elements are 3234367 and nodes 581744 . A higher number represents a longer simulation time, while the variation in the expected result (efficiency in BEP) is negligible [45-47]. Figure 7 presents a cross-sectional view. Finite element analysis (FEA) has a major focus on the corners and impeller blades, the critical area where the energy is transformed and has the largest number of structured elements [48]. The image shows two zoom areas of interest where these zones are rounded to guarantee the minimum mesh metrics, shown in Table 3, based on the software [49].

Table 2

Mesh independence

\begin{tabular}{llllll}
\hline Concept & Mesh 1 & Mesh 2 & Mesh 3 & Mesh 4 & Mesh 5 \\
\hline Mesh elements & 696899 & 1819335 & 2621229 & 3234367 & 5884949 \\
Nodes & 158417 & 330891 & 473692 & 581744 & 1046774 \\
Element size [m] & 0.3 & 0.2 & 0.16 & 0.14 & 0.10 \\
Time [min] & 55 & 60 & 80 & 105 & 190 \\
Face sizing [m] & 0.07 & 0.07 & 0.07 & 0.07 & 0.07 \\
Efficiency [\%] & 86.69 & 86.95 & 86.98 & 86.99 & 87.00 \\
Relative error [\%] & 7.02 & 7.34 & 7.38 & 7.40 & 7.40 \\
\hline
\end{tabular}


Table 3

Mesh metrics

\begin{tabular}{lll}
\hline Concept & Value & Ideal \\
\hline Aspect ratio & 12.732 & $<100$ \\
Expansion & 13 & $<20$ \\
Orthogonal quality & 0.203 & $>0.167$ \\
\hline
\end{tabular}

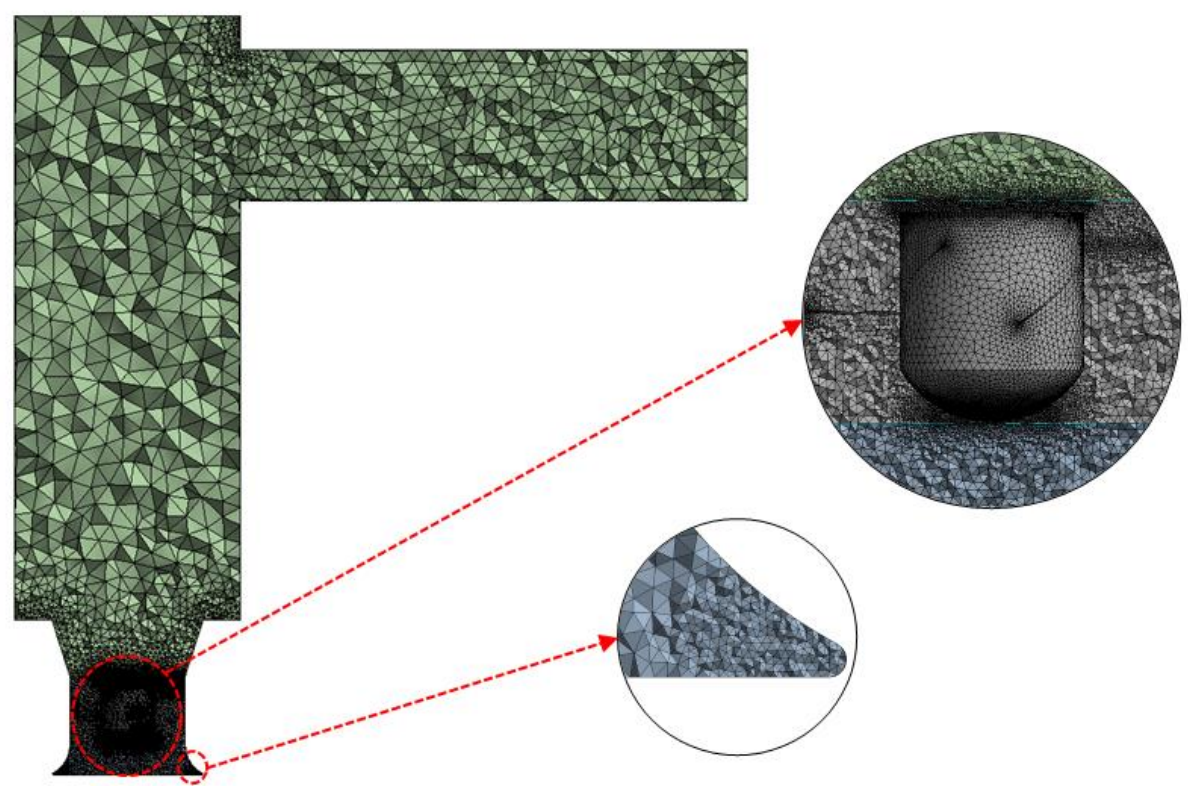

Fig. 7. Mesh applied to the control volume

\subsection{Step 4: Boundary Conditions in Pump Mode}

Figure 8 (a) reports the boundary conditions of all domains, while Figure 8 (b) shows the rotational domain, indicating the flow direction. The interface is configured at the inlet and outlet of the impeller control volume. It is detailed that the flow goes from the suction zone to the discharge.

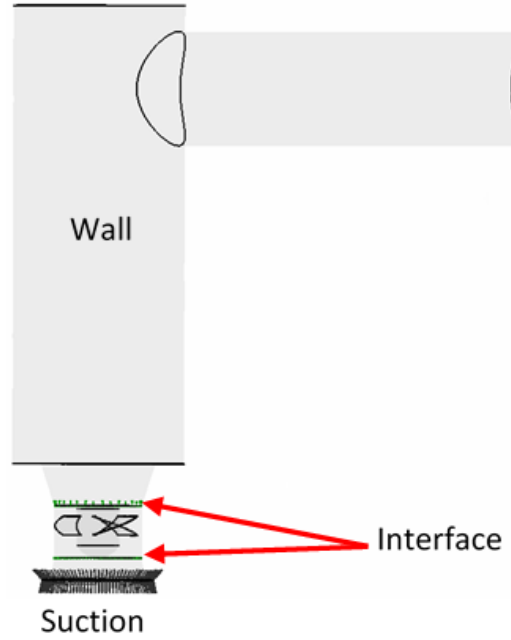

(a)
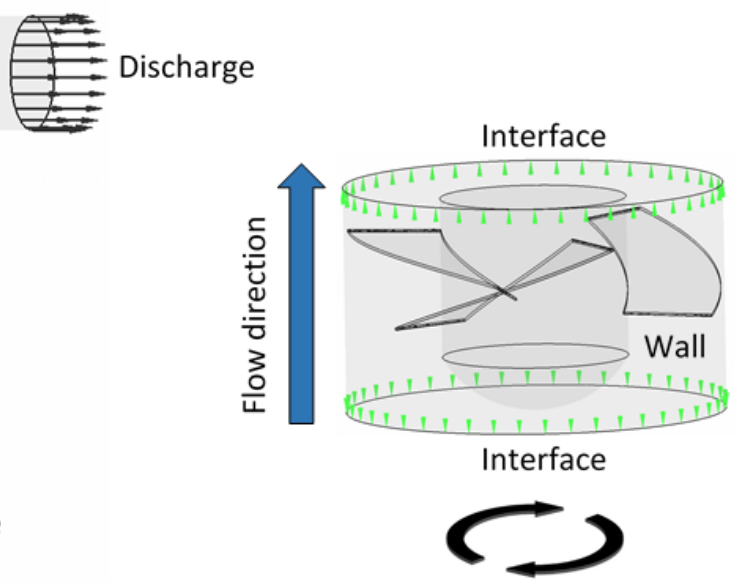

(b)

Fig. 8. Boundary conditions in pump mode: (a) all domains and (b) rotational domain 
The simulation is configured in pump mode. The analysis type is steady-state, supported by a numerical study on axial PAT [25], and theoretical-numerical analysis on radial PAT, with an error of less than $2 \%$ in the BEP [50]. The density of water is $997.1 \mathrm{~kg} \mathrm{~m}^{-3}$ at $25^{\circ} \mathrm{C}$, neglecting heat losses [51]. The interface is Frozen Rotor, used for this turbomachine [52]. The rotational domain is the control volume of the impeller, where the rotational speed is $1450 \mathrm{rpm}$, while the static domain is the housing. The input variable is relative pressure, set at $0 \mathrm{kPa}$. The output variable is mass flow rate, varying concerning the points shown in Figure 4. A total of 1000 iterations and a residual value of 0.0001 were established. Both parameters are key in the convergence of the simulation, where the latter refers to the desired error. In addition, the mesh quality is important in this analysis. However, it is crucial to clarify that the focus of the simulation is the control variable (head), so the simulation can converge in a smaller number of iterations. If this stabilizes, it is possible to stop the simulation and check the results, given the low residual value, which is usually 0.001 by default.

Numerical analysis is based on the partial differential equations of Navier-Stokes [53]. $k-\varepsilon$ is selected as a turbulence model due to its wide use, appropriate cost ratio, and simulation efficiency. This model has a lot of applications in several engineering domains [54]. It is a robust model that allows convergence in a short time, compared to turbulence models such as Reynolds Stress Model (RSM) or Detached Eddy Simulation (DES). On the other hand, a recent study has evidenced errors lower than 4\% in CFD studies compared with the experimental curve [55].

However, it does not adequately capture near-wall flow [56] and it is not very accurate for highpressure gradients [57]. Also, it is suitable for predicting fluid behavior in bulk regions [58]. Compared to other turbulence models, $\mathrm{k}-\varepsilon$ is suitable because of its low error concerning the SST and RNG model [59].

The governing equation for the steady-state is formulated by two separate transport equations: the kinetic turbulent energy $k$ and dissipation energy $\varepsilon[60]$. Through FEA and numerical methods, solutions can be calculated for these energies together with the eddy viscosity $\left(\mathrm{k}^{2} / \varepsilon\right)$ and the length scale $\left(k^{1.5} / \varepsilon\right)$, considering the time-averaged fluid velocity [61]. The mathematical model is shown in Eq. (1-3). On the other hand, Eqs. (4-6) model the kinetic energy and turbulent energy dissipation tensors, where $u$ is the velocity vector and $\nabla$ is the divergence operator.

$$
\begin{aligned}
& \frac{\partial\left(\rho \mathrm{ku}_{\mathrm{i}}\right)}{\partial \mathrm{x}_{\mathrm{i}}}=\frac{\partial}{\partial \mathrm{x}_{\mathrm{j}}}\left[\left(\mu+\frac{\mu_{\mathrm{t}}}{\rho_{\mathrm{k}}}\right) \frac{\partial \mathrm{k}}{\partial \mathrm{x}_{\mathrm{j}}}\right]+\mathrm{P}_{\mathrm{k}}-\rho \varepsilon \\
& \frac{\partial\left(\rho \varepsilon \mathrm{u}_{\mathrm{i}}\right)}{\partial \mathrm{x}_{\mathrm{i}}}=\frac{\partial}{\partial \mathrm{x}_{\mathrm{j}}}\left[\left(\mu+\frac{\mu_{\mathrm{t}}}{\rho_{\varepsilon}}\right) \frac{\partial \varepsilon}{\partial \mathrm{x}_{\mathrm{j}}}\right]+\mathrm{C}_{1 \varepsilon} \frac{\varepsilon}{\mathrm{k}} \mathrm{P}_{\mathrm{k}}-\mathrm{C}_{2 \varepsilon} \rho \frac{\varepsilon^{2}}{\mathrm{k}} \\
& \mu_{\mathrm{t}}=\rho \mathrm{C}_{\mu} \frac{\mathrm{k}^{2}}{\varepsilon}=\frac{1}{2}\left(\frac{\partial \mathrm{u}_{\mathrm{j}}}{\partial \mathrm{x}_{\mathrm{i}}}+\frac{\partial \mathrm{u}_{\mathrm{i}}}{\partial \mathrm{x}_{\mathrm{j}}}\right) \\
& \rho(\mathbf{u} \cdot \nabla) \mathbf{u}=\nabla \cdot\left[-\mathrm{pI}+\left(\mu+\mu_{\mathrm{T}}\right)\left(\nabla \mathbf{u}+\nabla \mathbf{u}^{\mathrm{T}}\right)\right] \\
& \nabla \cdot \mathbf{u}=0 \\
& \rho(\mathbf{u} \cdot \nabla) \mathrm{k}=\nabla \cdot\left[\left(\mu+\frac{\mu_{\mathrm{t}}}{\rho_{\mathrm{k}}}\right) \nabla \mathrm{k}\right]+P_{k}-\rho \varepsilon \\
& \rho(\mathbf{u} \cdot \nabla) \varepsilon=\nabla \cdot\left[\left(\mu+\frac{\mu_{\mathrm{t}}}{\rho_{\varepsilon}}\right) \nabla \varepsilon\right]+\mathrm{C}_{1 \varepsilon} \frac{\varepsilon}{\mathrm{k}} \mathrm{P}_{\mathrm{k}}-\mathrm{C}_{2 \varepsilon} \rho \frac{\varepsilon^{2}}{\mathrm{k}}
\end{aligned}
$$

Eq. (7) is used to find the head in pump and turbine mode and generate the numerical characteristic curve, which relates to the pressure difference $\left(P_{\text {outlet }}-P_{\text {inlet }}[\mathrm{Pa}]\right)$ to water-specific 
weight ( $\gamma=\rho g\left[\mathrm{~N} \mathrm{~m}^{-3}\right]$ ) [62]. Eq. (8) represents the machine efficiency in pump mode, which is the ratio of the power delivered to the fluid over the power input [63-65].

$$
\begin{aligned}
& H_{p, T}=\frac{P_{\text {outlet }}-P_{\text {inlet }}}{\rho g} \\
& \eta_{p}=\frac{\rho g H Q}{P} \cdot 100 \%
\end{aligned}
$$

The simulation is carried out in the CFX module of ANSYS ${ }^{\circledR}$ and performed for each point shown in Figure 4, where the mass flow rate is varied to find the head and thus be able to reconstruct the curve. As an alternative to mass flow rate, it is possible to use the velocity [66], although it is not usual for this type of turbomachinery.

\subsection{Step 6: Boundary Conditions in Turbine Mode}

Figure 9 shows the boundary conditions in turbine mode. In contrast to Figure 8, the suction and discharge are interchanged to modify the flow direction. The simulation is set up following the procedure of step 4 in pump mode. Eq. (7) is maintained to generate the characteristic curve, but the fraction of Eq. (8) is inverted because the fluid transmits the energy to the impeller [67]. Finally, different values of mass flow are proposed to determine the parameters such as head, efficiency, and power of the turbomachine.

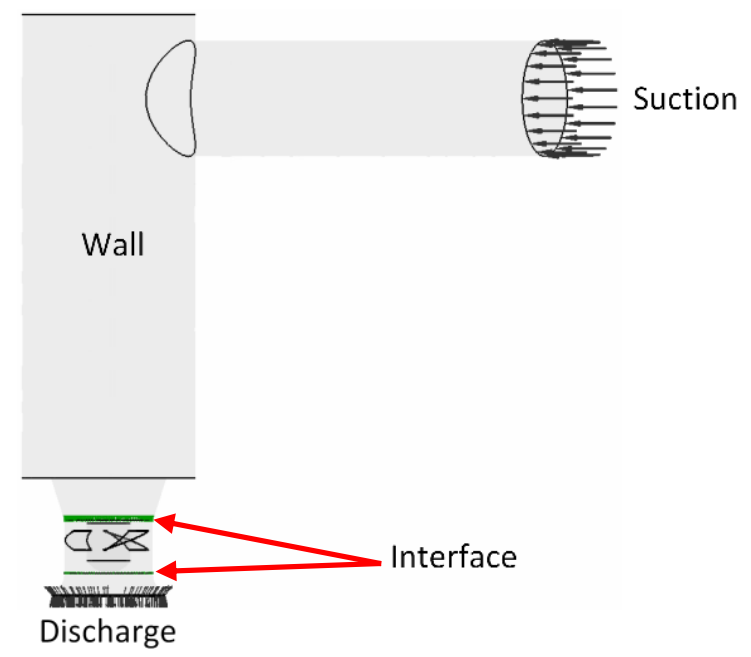

(a)

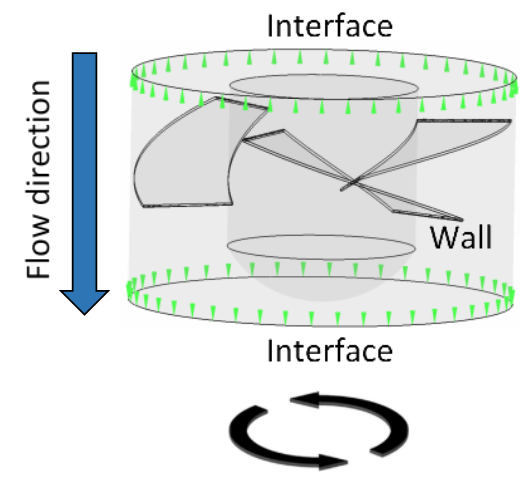

(b)

Fig. 9. Boundary conditions in turbine mode: (a) all domains and (b) rotational domain

\section{Results and Discussion}

\subsection{Step 5: Results and Validation in Pump Mode}

Figure 10 shows the comparison between numerical-CFD analysis and manufacturer characteristic curves in pump mode. The BEP results reveal a relative error of $7.41 \%$, where a numerical head of $3.02 \mathrm{~m}$ is obtained. The average error is $6.81 \%$. However, a maximum error of $12.71 \%$ is gotten, although this point is far from the BEP, causing unstable due to the part-load condition, which gives rise to possible pump stability impairments if operating under these conditions [68]. Regarding efficiency, an absolute error of $6.00 \%$ and an average of $5.09 \%$ are obtained. Finally, 
the relative error in power is $1.19 \%$. The power curve refers to the minimum value required by the electric motor to reach the described conditions, so when coupled, the power supplied should be higher, due to the electrical and mechanical losses generated.

Although the trend of the input power is decreasing, it has been evidenced that power increases with the reduction of the flow rate and increase of the head, for pumps with specific speeds higher than 120 [69], being for this case $329\left(\mathrm{rpm} \mathrm{m}^{3 / 4} \mathrm{~s}^{-1 / 2}\right)$.

On the other hand, the trend of the curve is similar to those found in the literature, where the head has a decreasing trend from lower to higher flow [27] and the efficiency is concave downward [30]. On the other hand, it is possible to identify that the BEP is located approximately at an intermediate point of the head curve, showing a partially symmetrical behavior with respect to efficiency. Finally, it is possible to verify that the flow range has a ratio of up to 1.7 , when comparing the maximum and minimum values, where the pump evaluated is close to 1.5 [23].

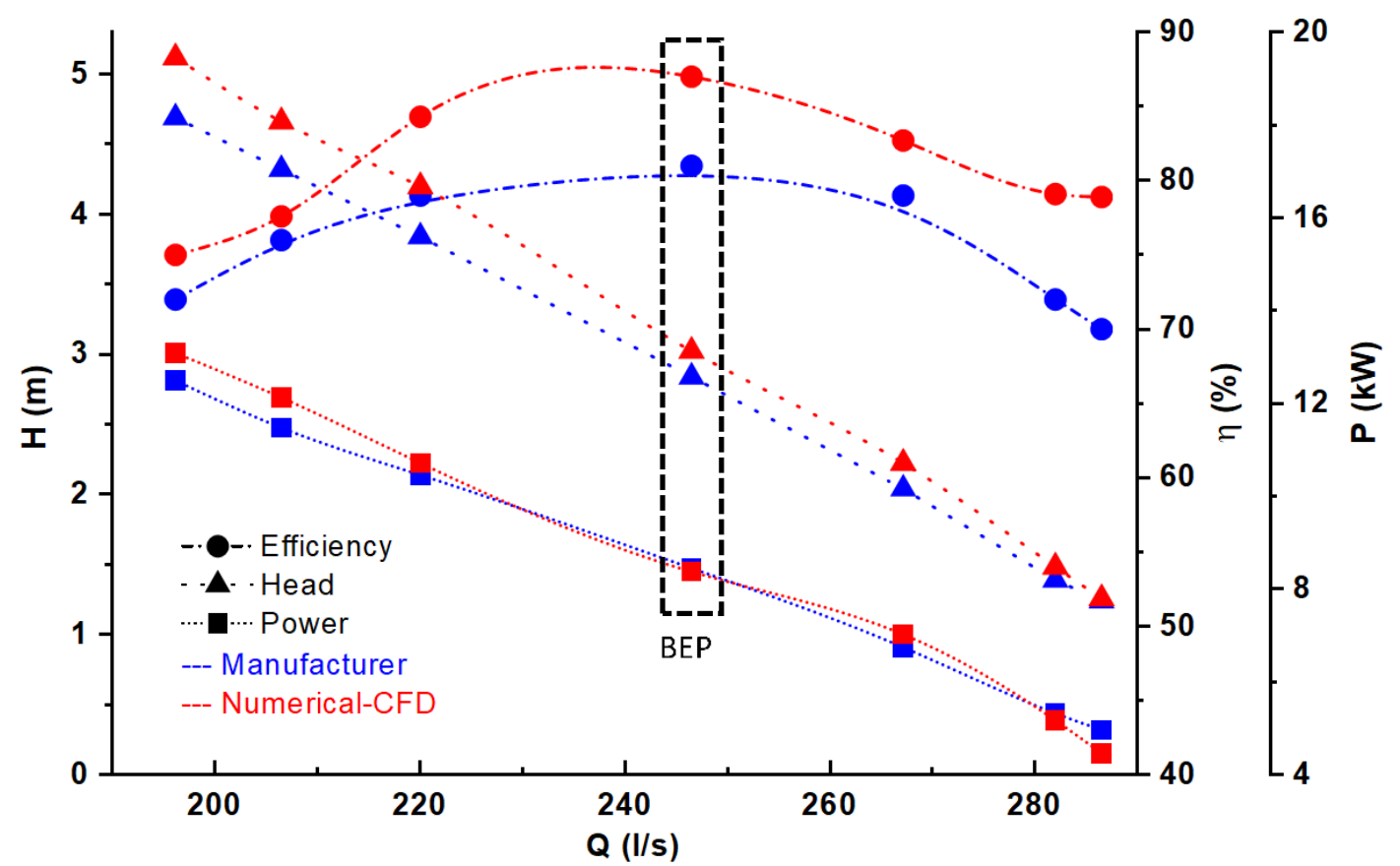

Fig. 10. Numerical-CFD and manufacturer characteristic curve in pump mode

Fluid dynamic results are presented using contours. Figure 11(a) shows the pressure behavior along the fluid direction, where arrows indicate the pumping direction. The pressure range analyzed is from $-10 \mathrm{kPa}$ to $155 \mathrm{kPa}$ for better visualization. A maximum pressure of $236.76 \mathrm{kPa}$ and a minimum value of $-334.15 \mathrm{kPa}$ are obtained, where the change is noted in the impeller volume, which is responsible for converting kinetic energy to flow energy.

Figure 11 (b) shows the velocity changes in the turbomachine. The range of analysis is $0-20 \mathrm{~m} \mathrm{~s}^{-1}$. It is expected that the velocity increases in the impeller, given the rotational speed. It is observed that as the fluid enters the housing, the velocity decreases drastically, compensating for the pressure increase, having a behavior like the contour of a 2D diffuser [70].

Figure 11(c) shows the pressure variation at the suction and discharge of the impeller blades. Leading Edge (LE) relates to suction conditions, where low pressure of $-334.15 \mathrm{kPa}$ is obtained, while Trailing Edge (TE) pressure is higher, reaching up to $120 \mathrm{kPa}$ since this is the zone where energy transformation takes place. In the walls is observed a low pressure, because in this area is not closed in contact with the impeller. The negative pressure is due to the suction effect caused by the impeller and possible cavitation formation. However, it is not significant in this analysis. 
Figure $11(\mathrm{~d})$ shows the direction of fluid displacement in the blade zone, where the minimum velocity is $8 \mathrm{~m} \mathrm{~s}^{-1}$ and an average of $15 \mathrm{~m} \mathrm{~s}^{-1}$. These results validate the numerical and fluid dynamic simulation in pump mode; for this reason, the simulation is continued in turbine mode since the errors obtained are lower than the proposed $10 \%$ in BEP.

In another study based on streamlines, the velocity gradually decreases as the fluid approaches the impeller walls (d). However, in the zone that is close to the housing, the velocity increases, because there is an existing separation with the impeller [28]. For this study, similar behavior can be seen, although the arrows between both elements are not evident because this space is very small compared to the impeller diameter.

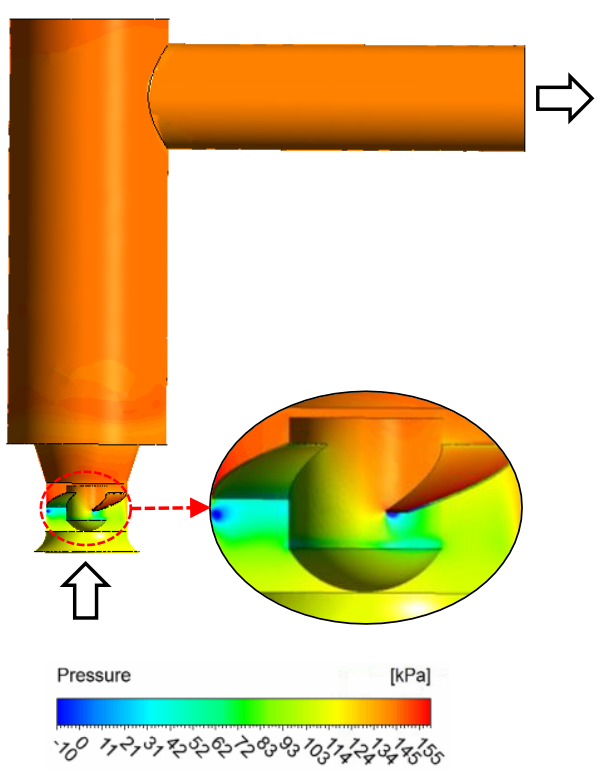

(a)

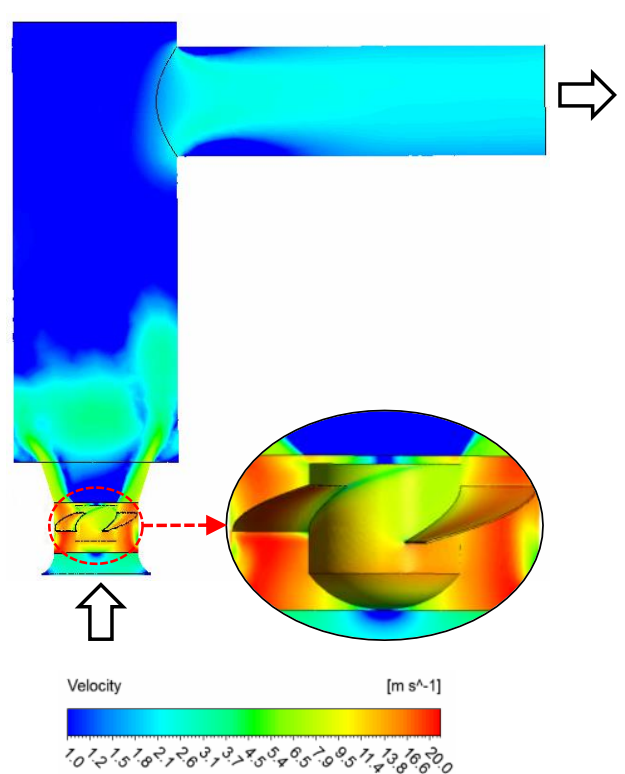

(b)

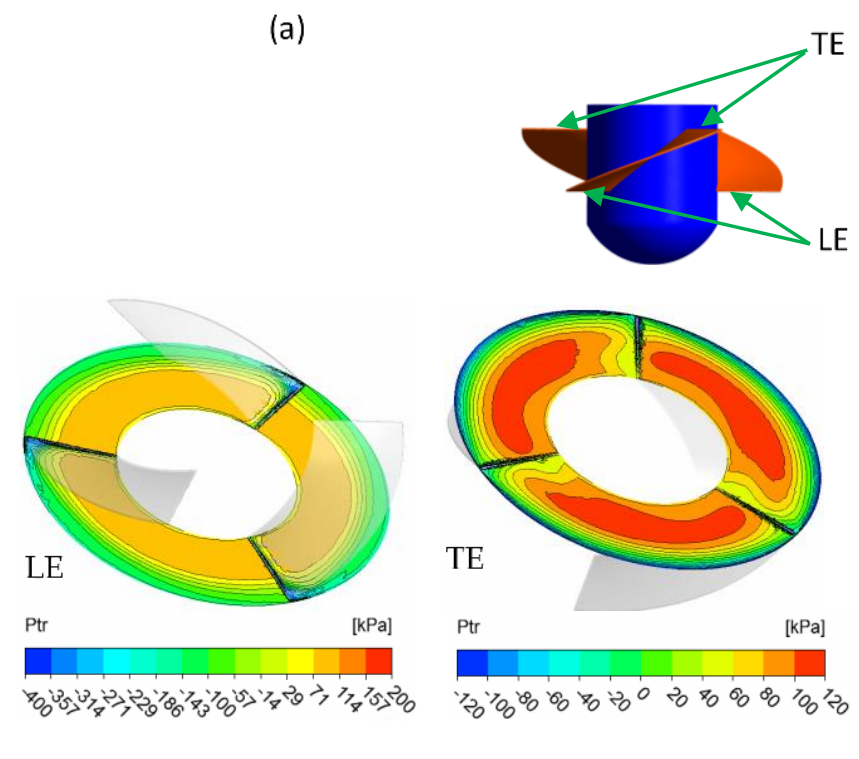

(c)

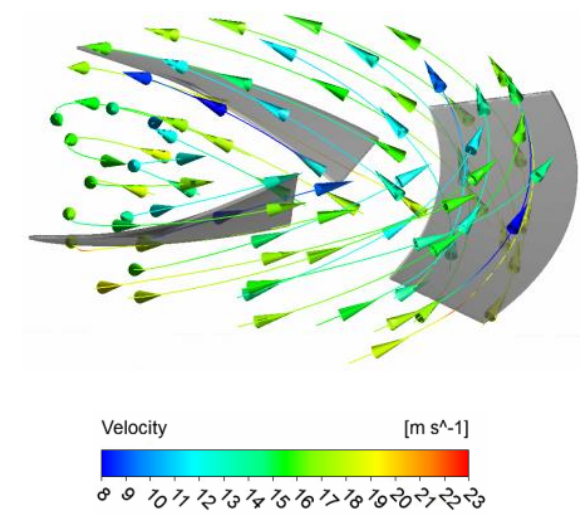

(d)

Fig. 11. Fluid dynamic validation in pump mode: (a) pressure in volume control; (b) velocity in volume control; (c) pressure in LE and TE; and (d) velocity in blade zone 


\subsection{Step 7: Characteristic Curve in Turbine Mode}

Figure 12 shows the numerical results of the axial flow PAT. The values indicate the site conditions: PAT head $\left(H_{T}\right) 7.40 \mathrm{~m}$, flow rate $\left(Q_{T}\right) 351.02 \mathrm{I} \mathrm{s}^{-1}$, efficiency $\left(\eta_{T}\right) 73.00 \%$, hydraulic power $\left(P_{T}\right) 18.54 \mathrm{~kW}$. It can be noted that the flow and head range is much larger than in pump mode. On the other hand, if the pump operates in a higher range of the site conditions, the power generated has an increasing trend, but energy conversion would not be efficient [71].

The trend of the curves could be corroborated with respect to the literature. One study reveals that as the blade angle is varied, the efficiency is maximum at $20^{\circ}$, with a similar trend to the present study [31]. On the other hand, the head grows exponentially, where it was consulted that the head triples, while the flow rate only increases by one-third [29]. Similar behavior can be verified in the range $350-450 \mathrm{I} \mathrm{s}^{-1}$, where the head increases 3.3 times.

Finally, similar behavior is verified concerning the flow rate range between the pump mode and turbine mode curve. When checking the point where the efficiency is acceptable (greater than 50\%), the corresponding flow rate is close to the pump mode intermediate, while the BEP is in a zone where the pump mode conditions are inefficient or out of range $[23,28]$.

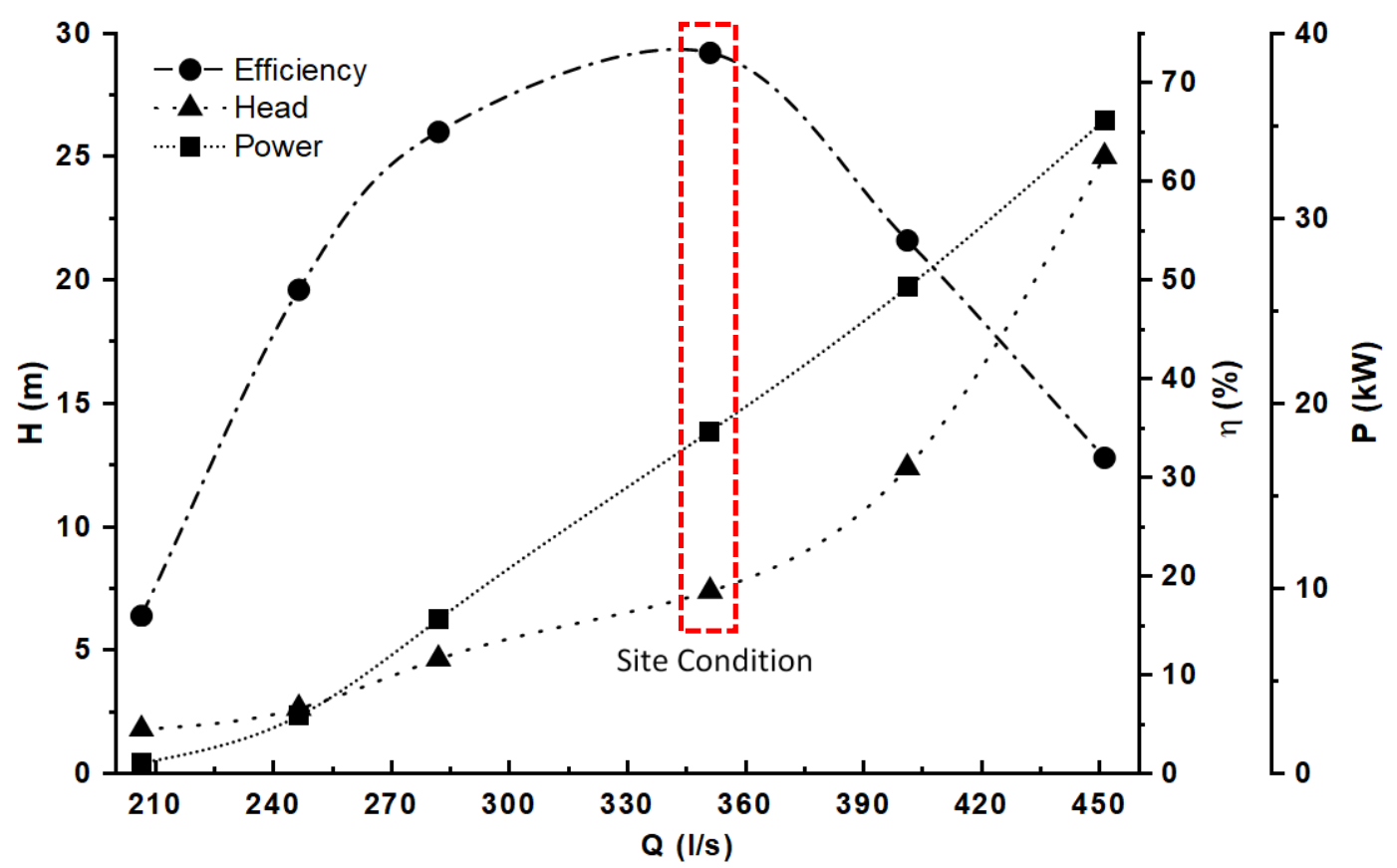

Fig. 12. Characteristic curve in turbine mode

Figure 13(a) validates the blade-to-blade fluid dynamic behavior of the pressure contour, showing the flow direction by arrows. Additionally, the right shows the Leading and Trailing Edge locations, which are inverse to the pump mode [72]. The range of analysis is $-20 \mathrm{kPa}$ to $144 \mathrm{kPa}$ for more detail, although the minimum pressure is $-195.60 \mathrm{kPa}$ and a maximum of $438.97 \mathrm{kPa}$. The variation shows that the highest pressure is before the impeller and then the pressure decreases as it moves along each vane because the impeller transforms the pressure into mechanical energy. The cavitation is very punctual in the Trailing-Edge, but it is not very significant in the numerical analysis. Similarly, Figure $13(\mathrm{~b})$ shows the velocity change in the blade region. The range of analysis is $0-24 \mathrm{~m} \mathrm{~s}^{-1}$. It can be detailed in Leading Edge that the velocity reaches its maximum value since it is the first point of contact between the fluid and the impeller. As the fluid streams between the blades, the velocity tends to decrease. On the right, the direction of the fluid in the blade zone is shown, being inverse to 
Figure $11(\mathrm{~d})$. The average velocity is $17 \mathrm{~m} \mathrm{~s}^{-1}$. With this, the kinetic and pressure energy is transferred to the impeller and converted into mechanical energy to produce work employing a generator.

The pressure contour is validated with a study using a PAT with guide vanes, where the pressure increases at the leading edge, while the pressure decreases as the fluid is expelled from the impeller [25]. The behavior is similar to the one obtained, since the fluid transfers its energy to the impeller, making it rotate thanks to its geometry.

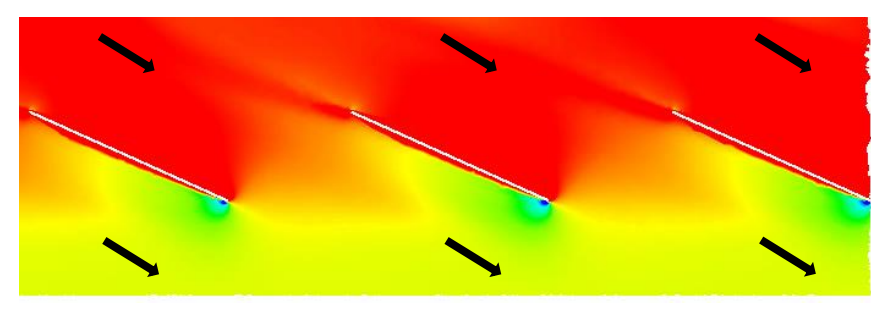

(a)

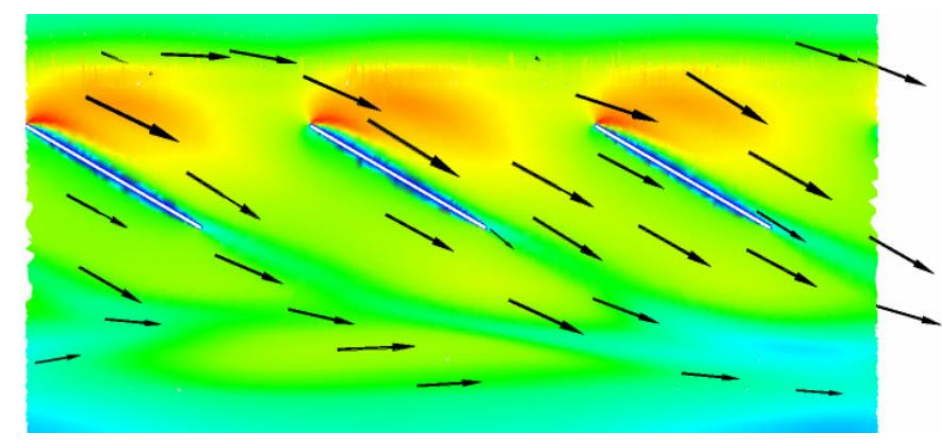

(b)
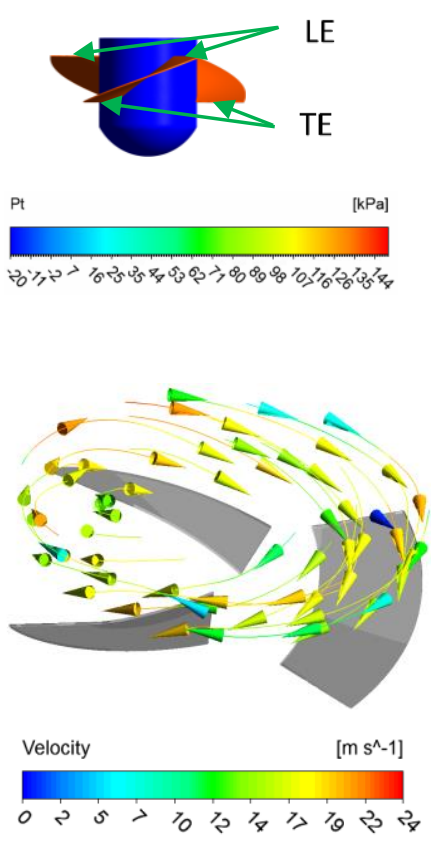

Fig. 13. Fluid dynamic blade-to-blade view in turbine mode: (a) pressure and (b) velocity

Finally, Figure 14 validates the axial PAT site conditions, using Figure 2(b). It is observed that the results are under the selection area of the analyzed pump, although the hydraulic power is close to $20 \mathrm{~kW}$, being this the power if the turbomachine had no energy losses. Table 4 shows the summary comparing the data obtained in both operating modes, where the values in parentheses are obtained from the characteristic curve in Figure 4. The efficiency in turbine mode is slightly lower, while the delivered flow and head are much higher. In comparison, the pressure and velocity in pump mode are lower than in turbine mode since the site conditions (head and flow) are of greater magnitude.

Table 4

Numerical comparison pump and turbine mode, at $1450 \mathrm{rpm}$

\begin{tabular}{lll}
\hline Variable & Pump mode & Turbine mode \\
\hline Head $[\mathrm{m}]$ & $3.02(2.84)$ & 7.40 \\
Flow $\left[\mathrm{I} \mathrm{s}^{-1}\right]$ & 246.45 & 351.02 \\
Efficiency [\%] & $87.00(81.00)$ & 73.00 \\
Hydraulic power $[\mathrm{kW}]$ & $8.30(8.40)$ & 18.54 \\
Max pressure $[\mathrm{kPa}]$ & 236.76 & 438.97 \\
Min pressure $[\mathrm{kPa}]$ & -334.15 & -195.60 \\
Max velocity $\left[\mathrm{m} \mathrm{s}^{-1}\right]$ & 20 & 24 \\
\hline
\end{tabular}




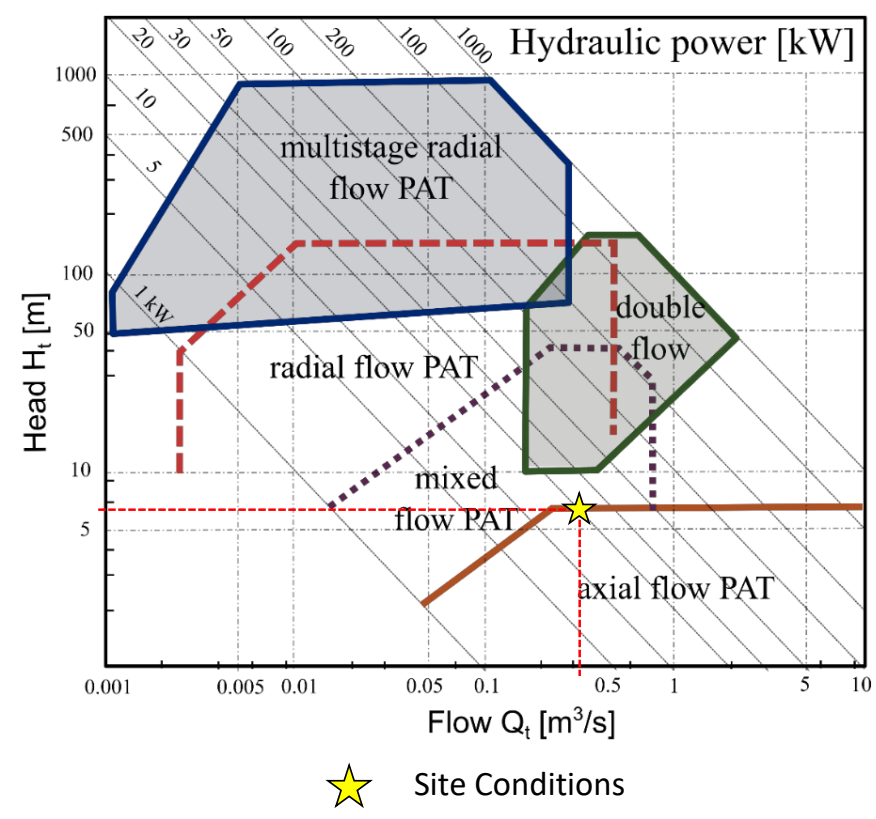

Fig. 14. Validation of site conditions of commercial axial flow PAT

Therefore, the present proposed methodology presents results consistent with expectations to the state of the art, to serve as a basis for future evaluations for axial flow pumps to support the energetic development of remote zones.

\section{Conclusion}

A replicable methodology is proposed through numerical and fluid dynamic simulations for the characterization of commercial axial flow centrifugal pumps for hydroelectric power generation to support the energetic development of the non-interconnected areas. Employing numerical and fluid dynamic simulations, the relative error of less than $10 \%$ proposed in the BEP in pump mode was achieved. In addition, the following was achieved:

i. In pump mode, an error lower than the proposed $10 \%$ was obtained: $7.41 \%$ in the BEP and validated through the characteristic curve and the fluid dynamic results. This error could be caused by the three-dimensional modeling because the modeling is not accurate to reality; the turbulence model, where selecting a more robust model would have a better approximation, although with a longer simulation time; three-dimensional meshing because the quality is not perfect.

ii. In turbine mode, the numerical simulation was carried out for different mass flow values, where a maximum efficiency of $73 \%$ was achieved, 8 units lower than the real efficiency given by the manufacturer.

iii. The curves obtained in both modes of operation were validated, showing a similar trend in efficiency and head with respect to the sources consulted.

iv. Although the PAT can be operated outside the site conditions to generate a higher power output, it is not recommended, since the energy conversion is inefficient. Therefore, it is recommended to select another turbomachine that operates in the expected site conditions (head and flow).

v. The pressure and velocity in turbine mode were lower than in pump mode since the site conditions were higher. 
vi. The results showed that, although there was no information on the impeller geometry, by using an approximate geometry, the error criterion of less than $10 \%$ proposed in this methodology was met, so this limitation does not represent an error greater than the one exposed, since a study of the particles inside the turbomachine was not carried out.

vii. Although this analysis focuses on axial flow PATs, it is not limited only to this type of flow. However, the relevance to mixed flow PATs should be evaluated, since the impeller trailing angle could generate disadvantages concerning the simulation configuration presented above.

viii. As future work, it is recommended to propose a step-by-step methodology for axial flow PATs, with a Lagrangian approach to perform particle studies to analyze instabilities in the turbomachinery.

\section{Acknowledgment}

The authors would like to thank the Materiales Avanzados y Energía research group (MATyER), especially the research line of Computación Avanzada y Diseño Digital y Procesos de Manufactura (SeCADD-ProM) and the system department of the Instituto Tecnológico Metropolitano (ITM), for allowing the use of the computer equipment and licenses of the software ANSYS ${ }^{\circledR}$ to perform the simulations.

\section{References}

[1] Day, John W., Christopher F. D'Elia, Adrian RH Wiegman, Jeffrey S. Rutherford, Charles AS Hall, Robert R. Lane, and David E. Dismukes. "The energy pillars of society: Perverse interactions of human resource use, the economy, and environmental degradation." Biophysical Economics and Resource Quality 3, no. 1 (2018): 1-16. https://doi.org/10.1007/s41247-018-0035-6

[2] Pinkse, Jonatan, and Koen Groot. "Sustainable entrepreneurship and corporate political activity: Overcoming market barriers in the clean energy sector." Entrepreneurship Theory and Practice 39, no. 3 (2015): 633-654. https://doi.org/10.1111/etap.12055

[3] REN21 Secretariat. "Renewables 2019 Global Status Report." REN21 Renewables Now, Paris, France (2019).

[4] Vásquez, Diego Penagos, and Daniel Sanín Villa. "Parametric and Economic Analysis of a Pumped Storage System Powered by Renewable Energy Sources." Journal of Advanced Research in Fluid Mechanics and Thermal Sciences 84, no. 1 (2021): 43-59. https://doi.org/10.37934/arfmts.84.1.4359

[5] Williamson, Sam J., Bernard H. Stark, and Julian D. Booker. "Low head pico hydro turbine selection using a multicriteria analysis." Renewable Energy 61 (2014): 43-50. https://doi.org/10.1016/j.renene.2012.06.020

[6] "Ensure access to affordable, reliable, sustainable and modern energy - United Nations Sustainable Development." United Nations. Accessed July 17, 2021.

[7] IHA Central Office. "Hydropower status report 2020." International Hydropower Association, London, UK (2020).

[8] International Hydropower Association. "Hydropower status report.", London, UK, (2020).

[9] Acolgen. "Mapa de Generación Eléctrica en Colombia." Colombian Association of Electric Power Generators, Acolgen, July 17, 2021.

[10] “Mapas - Upme." Upme. Accessed May 30, 2021.

[11] Chapallaz, Jean-Marc, Peter Eichenberger, and Gerhard Fischer. Manual on pumps used as turbines. Vieweg, Braunschweig, Germany, 1992.

[12] Graciano-Uribe, Jonathan, Jorge Sierra, and Edwar Torres-López. "Instabilities and influence of geometric parameters on the efficiency of a pump operated as a turbine for micro hydro power generation: A review." Journal of Sustainable Development of Energy, Water and Environment Systems (2020). https://doi.org/10.13044/j.sdewes.d8.0321

[13] Ranjitkar, Ghanashyam, Jinxing Huang, and Tony Tung. "Application of micro-hydropower technology for remote regions." In 2006 IEEE EIC Climate Change Conference, pp. 1-10. IEEE, 2006. https://doi.org/10.1109/EICCCC.2006.277207

[14] Zhang, Hua, Wei-dong Shi, Chen Bin, Qi-hua Zhang, and Wei-dong Cao. "Experimental study of flow field in interference area between impeller and guide vane of axial flow pump." Journal of Hydrodynamics, Ser. B 26, no. 6 (2015): 894-901. https://doi.org/10.1016/S1001-6058(14)60098-6 
[15] Mu, Tong, Rui Zhang, Hui Xu, Yuan Zheng, Zhaodan Fei, and Jinghong Li. "Study on improvement of hydraulic performance and internal flow pattern of the axial flow pump by groove flow control technology." Renewable Energy 160 (2020): 756-769. https://doi.org/10.1016/i.renene.2020.06.145

[16] Derakhshan, Shahram, and Ahmad Nourbakhsh. "Experimental study of characteristic curves of centrifugal pumps working as turbines in different specific speeds." Experimental Thermal and Fluid Science 32, no. 3 (2008): 800-807. https://doi.org/10.1016/i.expthermflusci.2007.10.004

[17] Fernández, J., R. Barrio, E. Blanco, J. L. Parrondo, and A. Marcos. "Numerical investigation of a centrifugal pump running in reverse mode." Proceedings of the Institution of Mechanical Engineers, Part A: Journal of Power and Energy 224, no. 3 (2010): 373-381. https://doi.org/10.1243/09576509JPE757

[18] Delgado, J., J. P. Ferreira, D. I. C. Covas, and F. Avellan. "Variable speed operation of centrifugal pumps running as turbines. $\quad$ Experimental investigation." Renewable $\quad$ Energy $142 \quad$ (2019): https://doi.org/10.1016/i.renene.2019.04.067

[19] Jiang, W., Z. L. Liu, Y. C. Wang, J. G. Yang, and G. Y. Hou. "Numerical Investigation of the Clocking Effect on the Centrifugal Pump as Turbine." In IOP Conference Series: Earth and Environmental Science, vol. 701, no. 1, p. 012035. IOP Publishing, 2021. https://doi.org/10.1088/1755-1315/701/1/012035

[20] Lin, Tong, Xiaojun Li, Zuchao Zhu, Jing Xie, Yi Li, and Hui Yang. "Application of enstrophy dissipation to analyze energy loss in a centrifugal pump as turbine." Renewable Energy 163 (2021): 41-55. https://doi.org/10.1016/i.renene.2020.08.109

[21] Maleki, Ali, Mohammad Mahdi Ghorani, Mohammad Hadi Sotoude Haghighi, and Alireza Riasi. "Numerical study on the effect of viscosity on a multistage pump running in reverse mode." Renewable Energy 150 (2020): $234-254$. https://doi.org/10.1016/i.renene.2019.12.113

[22] Rakibuzzaman, Md, Keum-Young Jung, and Sang-Ho Suh. "A study on the use of existing pump as turbine." In E3S Web of Conferences, vol. 128, p. 06004. EDP Sciences, 2019. https://doi.org/10.1051/e3sconf/201912806004

[23] Han, Yadong, and Lei Tan. "Dynamic mode decomposition and reconstruction of tip leakage vortex in a mixed flow pump as turbine at pump mode." Renewable Energy 155 (2020): $725-734$. https://doi.org/10.1016/i.renene.2020.03.142

[24] Chen, Jun, Tao Dai, and Qing Yang. "Effect of Rotational Speed on Performance of Mixed Flow Pump as Turbine." Shock and Vibration 2021 (2021). https://doi.org/10.1155/2021/6681953

[25] Renzi, Massimiliano, Pavel Rudolf, David Štefan, Alessandra Nigro, and Mosè Rossi. "Installation of an axial Pumpas-Turbine (PaT) in a wastewater sewer of an oil refinery: A case study." Applied Energy 250 (2019): 665-676. https://doi.org/10.1016/j.apenergy.2019.05.052

[26] Rawal, Sonia, and J. T. Kshirsagar. "Numerical simulation on a pump operating in a turbine mode." In Proceedings of the 23rd international pump users symposium. Texas A\&M University. Turbomachinery Laboratories, 2007. https://doi.org/10.21423/R1WD5C

[27] Cao, Weidong, and Wei Li. "Study on the Performance Improvement of Axial Flow Pump's Saddle Zone by Using a Double Inlet Nozzle." Water 12, no. 5 (2020): 1493. https://doi.org/10.3390/w12051493

[28] Qian, Zhongdong, Fan Wang, Zhiwei Guo, and Jie Lu. "Performance evaluation of an axial-flow pump with adjustable guide vanes in turbine mode." Renewable Energy 99 (2016): 1146-1152. https://doi.org/10.1016/j.renene.2016.08.020

[29] Bozorgi, A., E. Javidpour, A. Riasi, and A. Nourbakhsh. "Numerical and experimental study of using axial pump as turbine in pico hydropower plants." Renewable Energy $53 \quad$ (2013): $258-264$. https://doi.org/10.1016/i.renene.2012.11.016

[30] Zhou, Ying, Yuan Zheng, Kan Kan, Yuquan Zhang, Haolan Wang, Wei Tang, and Mengshang Zhao. "Study on hydraulic characteristics of large vertical axial-flow pump used as constant frequency power generation." Proceedings of the Institution of Mechanical Engineers, Part A: Journal of Power and Energy 235, no. 1 (2021): 5969. https://doi.org/10.1177/0957650920912089

[31] Bozorgi, A., A. Riasi, and A. Nourbakhsh. "Investigation of effects of changing blade position and size reduction on performance of axial pump used as turbine." In Applied Mechanics and Materials, vol. 110, pp. 2933-2939. Trans Tech Publications Ltd, 2012. https://doi.org/10.4028/www.scientific.net/AMM.110-116.2933

[32] Hötzl, Stephan, Tobias Schechtl, Peter Rutschmann, and Wilfried Knapp. "Development of a low head tidal turbine." International Marine Energy Journal 1, no. 2 (Nov) (2018): 81-90. https://doi.org/10.36688/imej.1.81-90

[33] Venturini, Mauro, Stefano Alvisi, Silvio Simani, and Lucrezia Manservigi. "Comparison of different approaches to predict the performance of pumps as turbines (PATs)." Energies 11, no. 4 (2018): 1016. https://doi.org/10.3390/en11041016

[34] Barbarelli, S., M. Amelio, and G. Florio. "Predictive model estimating the performances of centrifugal pumps used as turbines." Energy 107 (2016): 103-121. https://doi.org/10.1016/j.energy.2016.03.122 
[35] Amelio, Mario, Silvio Barbarelli, and Domenico Schinello. "Review of Methods Used for Selecting Pumps as Turbines (PATs) and Predicting Their Characteristic Curves." Energies 13, no. 23 (2020): 6341. https://doi.org/10.3390/en13236341

[36] Vásquez, Diego Penagos, Jonathan Graciano Uribe, Sebastián Vélez García, and Jorge Sierra del Rio. "Characteristic Curve Prediction of a Commercial Centrifugal Pump Operating as a Turbine Through Numerical Simulations." Journal of Advanced Research in Fluid Mechanics and Thermal Sciences 83, no. 1 (2021): $153-169$. https://doi.org/10.37934/arfmts.83.1.153169

[37] Miao, Sen-chun, Jun-hu Yang, Guang-tai Shi, and Ting-ting Wang. "Blade profile optimization of pump as turbine." $\begin{array}{llllll}\text { Advances in mechanical engineering } 7, \quad \text { no. } 9 & \text { (2015): } 1687814015605748 .\end{array}$ https://doi.org/10.1177/1687814015605748

[38] Sen-Chun, Miao, Shi Zhi-Xiao, Wang Xiao-Hui, Shi Feng-Xia, and Shi Guang-Tai. "Impeller meridional plane optimization of pump as turbine." Science progress 103, no. 1 (2020): 0036850419876542. https://doi.org/10.1177/0036850419876542

[39] Li, D. H., Y. Zhao, and G. Y. Wang. "Global design optimization for an axial-flow tandem pump based on surrogate method." In IOP Conference Series: Materials Science and Engineering, vol. 52, no. 2, p. 022013. IOP Publishing, 2013. https://doi.org/10.1088/1757-899X/52/2/022013

[40] Stefanizzi, Michele, Tommaso Capurso, Gabriella Balacco, Mario Binetti, Sergio Mario Camporeale, and Marco Torresi. "Selection, control and techno-economic feasibility of Pumps as Turbines in Water Distribution Networks." Renewable Energy 162 (2020): 1292-1306. https://doi.org/10.1016/i.renene.2020.08.108

[41] Yang, Sun-Sheng, Shahram Derakhshan, and Fan-Yu Kong. "Theoretical, numerical and experimental prediction of pump as turbine performance." Renewable Energy 48 (2012): https://doi.org/10.1016/i.renene.2012.06.002

[42] Su, Xianghui, Si Huang, Xuejiao Zhang, and Sunsheng Yang. "Numerical research on unsteady flow rate characteristics of pump as turbine." Renewable Energy $94 \quad$ (2016): 488-495. https://doi.org/10.1016/i.renene.2016.03.092

[43] Oreste, Fecarotta, Messa Gianandrea Vittorio, and Pugliese Francesco. "Numerical assessment of the vulnerability to impact erosion of a pump as turbine in a water supply system." Journal of Hydroinformatics 22, no. 4 (2020): 691-712. https://doi.org/10.2166/hydro.2020.140

[44] “AVS Sumersible Axial Flow Pumps." DP Pumps. Accessed May 17, 2021.

[45] Prasanna, Ramprasad, Prakash Moorthy, Aravind Krishnan, and Venkatesh Balakrishnan. "Analysis and optimization of radiant cooling panel with wave-type embedded pipes." Engineering Transactions 68, no. 1 (2020): 47-67. https://doi.org/10.24423/EngTrans.1035.20200102

[46] Binama, Maxime, Wen-Tao Su, Wei-Hua Cai, Xiao-Bin Li, Alexis Muhirwa, Biao Li, and Emmanuel Bisengimana. "Blade trailing edge position influencing pump as turbine (PAT) pressure field under part-load conditions." Renewable Energy 136 (2019): 33-47. https://doi.org/10.1016/i.renene.2018.12.077

[47] Prakoso, Aji Putro, Warjito Warjito, Ahmad Indra Siswantara, Budiarso Budiarso, and Dendy Adanta. "Comparison Between 6-DOF UDF and Moving Mesh Approaches in CFD Methods for Predicting Cross-Flow PicoHydro Turbine Performance." CFD Letters 11, no. 6 (2019): 86-96.

[48] JAHANGIRI, Ali, Seyed Ebrahim Moussavi TORSHIZI, and Seyed Majid Yadavar NIKRAVESH. "Failure analysis (experimental and numerical approach) of gas turbine generator cooling fan in comparison between using 2types (14० and 19॰ angle of attack) of blades." Engineering Transactions 61, no. 2 (2013): 99-117.

[49] ANSYS. ANSYS CFX-Solver Modeling Guide. Release 14.0. ANSYS, Inc., (2011).

[50] Wang, Longyan, Stephen Ntiri Asomani, Jianping Yuan, and Desmond Appiah. "Geometrical Optimization of PumpAs-Turbine (PAT) Impellers for Enhancing Energy Efficiency with 1-D Theory." Energies 13, no. 16 (2020): 4120. https://doi.org/10.3390/en13164120

[51] Mott, Robert L. Mecanica de Fluidos 6/e. Pearson educación, 2006.

[52] “2.3.1 The Multiple Reference Frame Model.” ANSYS. Accessed July 29, 2021.

[53] SÁNCHEZ, Alejandro RUIZ, Angie GUEVARA MUÑOZ, Jorge Andrés Sierra Del Rio, and Jose Alejandro POSADA MONTOYA. "Numerical comparison of two runners for gravitational vortex turbine." Engineering Transactions 69, no. 1 (2021): 3-17. https://doi.org/10.24423/EngTrans.1165.20210126

[54] Abd Rahman, Muhammad Faqhrurrazi, Suzairin MD Seri, Nor Zelawati Asmuin, Ishkrizat Taib, and Nur Syakirah Rabiha Rosman. "Response Surface Methodology (RSM) Approach for Optimizing the Actuator Nozzle Design of Pressurized Metered-Dose Inhaler (pMDI)." CFD Letters 13, no. 7 (2021): $27-44$. https://doi.org/10.37934/cfdl.13.7.2744

[55] Štefan, David, Mosè Rossi, Martin Hudec, Pavel Rudolf, Alessandra Nigro, and Massimiliano Renzi. "Study of the internal flow field in a pump-as-turbine (PaT): Numerical investigation, overall performance prediction model and velocity vector analysis." Renewable Energy 156 (2020): 158-172. https://doi.org/10.1016/i.renene.2020.03.185 
[56] Yusuf, Siti Nurul Akmal, Yutaka Asako, Nor Azwadi Che Sidik, Saiful Bahri Mohamed, and Wan Mohd Arif Aziz Japar. "A Short Review on RANS Turbulence Models." CFD Letters 12, no. 11 (2020): 83-96. https://doi.org/10.37934/cfdl.12.11.8396

[57] Bardina, J., P. Huang, T. Coakley, J. Bardina, P. Huang, and T. Coakley. "Turbulence modeling validation." In 28th Fluid dynamics conference, p. 2121. 1997. https://doi.org/10.2514/6.1997-2121

[58] Ghorani, Mohammad Mahdi, Mohammad Hadi Sotoude Haghighi, Ali Maleki, and Alireza Riasi. "A numerical study on mechanisms of energy dissipation in a pump as turbine (PAT) using entropy generation theory." Renewable Energy 162 (2020): 1036-1053. https://doi.org/10.1016/i.renene.2020.08.102

[59] Siswantara, Ahmad Indra, Budiarso Budiarso, Aji Putro Prakoso, Gun Gun R. Gunadi, Warjito Warjito, and Dendy Adanta. "Assessment of turbulence model for cross-flow pico hydro turbine numerical simulation." CFD Letters 10, no. 2 (2018): 38-48.

[60] Marazioti, P., and P. Koutmos. "Simulations of combustion roar in turbulent attached and lifted turbulent methane jet flames." Engineering Transactions 57, no. 3-4 (2009): 127-144.

[61] Yoon, Gil Ho. "Topology optimization method with finite elements based on the k- $\varepsilon$ turbulence model." Computer Methods in Applied Mechanics and Engineering 361 (2020): 112784. https://doi.org/10.1016/i.cma.2019.112784

[62] Lorusso, Michele, Tommaso Capurso, M. Torresi, B. Fortunato, F. Fornarelli, S. M. Camporeale, and Rosario Monteriso. "Efficient CFD evaluation of the NPSH for centrifugal pumps." Energy Procedia 126 (2017): 778-785. https://doi.org/10.1016/j.egypro.2017.08.262

[63] Mataix, Claudio. Turbomáquinas hidráulicas. Editorial ICAl, Madrid (1975).

[64] Mataix, Claudio. Mecánica de fluidos y máquinas hidráulicas. No. 620.106 M38 2012. Harla, 1982.

[65] Empaling, Shirly, Ahmad Zahran Md Khudzari, Muhammad Rashidi Abdul Kadir, Kahar Osman, Akmal Hakim Mohamad Hudzari, Mohammad Hasbullah Padzillah, Ishkrizat Abdul Talib, Mohamed Ezani Abdul Taib, and Aizai Azan Abdul Rahim. "Spiral Groove Bearing Geometry Variation Effect on Left Ventricular Assist Device Impeller Performance." CFD Letters 11, no. 1 (2019): 86-101.

[66] Gurunathan, Balamurugan A., Uswah Khairuddin, Nazrun Nabill Azlan Shah, and Ricardo Martinez-Botas. "Influence of Double Entry Volute on Incidence Angle Variation Under Steady Flow: Numerical Investigation." CFD Letters 12, no. 10 (2020): 75-89. https://doi.org/10.37934/cfdl.12.10.7589

[67] Lin, Tong, Zuchao Zhu, Xiaojun Li, Jian Li, and Yanpi Lin. "Theoretical, experimental, and numerical methods to predict the best efficiency point of centrifugal pump as turbine." Renewable Energy 168 (2021): 31-44. https://doi.org/10.1016/i.renene.2020.12.040

[68] Muggli, Felix A., Peter Holbein, and Philippe Dupont. "CFD calculation of a mixed flow pump characteristic from shutoff to maximum flow." J. Fluids Eng. 124, no. 3 (2002): 798-802. https://doi.org/10.1115/1.1478061

[69] Shen, Simin, Zhongdong Qian, and Bin Ji. "Numerical analysis of mechanical energy dissipation for an axial-flow pump based on entropy generation theory." Energies 12, no. 21 (2019): 4162. https://doi.org/10.3390/en12214162

[70] Elsayed, Ahmed M. "Design Optimization of Diffuser Augmented Wind Turbine." CFD Letters 13, no. 8 (2021): 4559. https://doi.org/10.37934/cfdl.13.8.4559

[71] Shi, Lijian, Fangping Tang, Hanlong Zhou, Lianlian Tu, and Rongsheng Xie. "Axial-flow pump hydraulic analysis and experiment under different swept-angles of guide vane." Transactions of the Chinese Society of Agricultural Engineering 31, no. 14 (2015): 90-95.

[72] Tao, Ran, Ruofu Xiao, Fujun Wang, and Weichao Liu. "Cavitation behavior study in the pump mode of a reversible pump-turbine." Renewable Energy 125 (2018): 655-667. https://doi.org/10.1016/i.renene.2018.02.114 